\title{
Epidemiological Study on Highly Pathogenic Avian Influenza H5N1 Virus with Modeling the Impact of Climate Variability on Outbreak Occurrence in Some Governorates of Nile Delta, Egypt
}

\author{
Yumna Elsobky ${ }^{1}$, Ahmed Byomi ${ }^{1}$, Gamal El Afandi ${ }^{2,3}$, Mona Aly ${ }^{4}$, Sherif Zidan ${ }^{1}$ and Ghada Hadad ${ }^{1}$ \\ ${ }^{1}$ Department of Hygiene and Zoonosis, Faculty of Veterinary Medicine, University of Sadat City, Egypt \\ ${ }^{2}$ College of Agriculture, Environment and Nutrition Sciences, Tuskegee University, Tuskegee, AL 36088, USA \\ ${ }^{3}$ Astronomy and Meteorology Department, Faculty of Science, Al Azhar University, Cairo 11884, Egypt \\ ${ }^{4}$ National Laboratory for Veterinary Quality Control on Poultry Production, Animal Health Research Institute, Dokki, Giza, Egypt \\ * Corresponding author's Email: yumna.elsobky@vet.usc.edu.eg; (DorCiD: 0000-0001-6881-3479
}

\begin{abstract}
Highly Pathogenic Avian Influenza (HPAI) H5N1 virus is widely circulated between poultry flocks in Egypt. The present study described the spatiotemporal dynamics of HPAI H5N1 in five Nile Delta governorates, Egypt (Dakhlia, Qalyobia, Sharkia, Gharbia, and Menofia) where most cases were reported for the years 2006 to 2016. Moreover, this study explored the impact of climate variability in outbreaks occurrence using the statistical generalized estimating equation model. The highest prevalence rate was recorded in Dakhlia and Qalyobia governorates, while Menofia governorate had the lowest one. From 2006 to 2009, the classic clade 2.2.1 was predominant and remained stable. It was demonstrated that new unreported clades had been evolved from classic clades after the vaccination pressure until 2010 resulted in raising the PR sharply. The stability of PR from 2012 to 2014 could be attributed to the adaptation of 2.2.1.2 endemic clade. The generalized estimating equation model revealed that a one-unit increase in maximum and minimum temperature decreased the risk of a poultry outbreak by about $6 \%$ and $4 \%$, respectively. According to the obtained results, it seems that the virus circulates and causes infection throughout the year, indicating changes in virus epidemiology and temporal patterns.
\end{abstract}

Key words: Epidemiology, Generalized estimating equation, Highly pathogenic avian influenza (HPAI)-H5N1 virus, Nile Delta governorates.

\section{INTRODUCTION}

Highly Pathogenic Avian Influenza (HPAI) subtype H5N1 is a transboundary animal disease that is transmitted to humans and over the past decade has a huge impact on the poultry industry and human health (Zhang et al., 2012). HPAI virus subtype H5N1 was first discovered in 1996 in Guangdong province of China (Xu et al., 1999). It was only recorded in China and Hong Kong for several years, resulting in human fatalities (Claas et al., 1998). Then the virus spread and caused new outbreaks in late 2003 and 2004 in several other Asian countries, including Vietnam, Thailand, Lao, Cambodia, Indonesia, Japan and South Korea. In the summer of 2005, it spread westwards and new outbreaks were reported from Kazakhstan and Russia. This was soon followed by outbreaks reported in Europe and African countries in autumn and winter of the same year. During the entire period from 2003 to 2011, the virus was distributed across 60 Asian, European and African countries (FAO, 2009; WAHID, 2011). Although many countries have succeeded in eliminating the HPAI H5N1 virus after the outbreaks first reported between 2003 and 2006, the virus still persists in some countries, including China, Indonesia, Vietnam, Bangladesh as well as Egypt (FAO, 2013), where the disease is endemic causing human cases (Abdelwhab and Hafez, 2011). Between November 2014 and April 2015, human cases detected by the Egyptian National Health showed the highest rate comparing to other countries over a similar period with a case fatality rate of $33 \%$ (WHO-EMRO, 2015).

Since 2009, the virus temporal pattern has greatly altered due to the occurrence of the outbreaks in the warmer months of the year (Abdelwhab and Hafez, 2011). Several risk factors for the spread and maintenance of HPAI H5N1 virus have been reported in previous literature. Climatic factors are one of the potential risk factors which greatly affect the whole process of the outbreak occurrence (Zhang et al., 2010). Unfortunately, the studies investigated the impacts of air temperature on H5N1 outbreaks are scarce (Gilbert et al., 2008).

Especially in Nile Delta, more investigation on climatic studies should be conducted to determine the conditions that favor the persistence and circulation of the virus in the environment (Abdelwhab et al., 2010). A limited number of countries that reported HPAI H5N1 cases have been subject to dedicated studies, whilst the results from those descriptive studies were highly location-specific (Gilbert and Pfeiffer, 2012). Intermittent and sporadic poultry outbreaks still are 
reported worldwide, despite the application of different disease control measures such as stamping-out, vaccination, quarantine, disinfection, and animal culling (Capua and Alexander, 2010). The possibility of human to human transmission and subsequently a human pandemic is increasing due to adaptive mutation and genetic re-assortment of the H5N1 virus (Park and Glass, 2007; Pfeiffer et al., 2007). The strongest factor for human infection is contact with sick or dead poultry (Zhou et al., 2009). Hence, it is crucial to control the virus in poultry to prevent human infection (Yupiana et al., 2010; Zhou et al., 2009). The comprehension of virus spread patterns during outbreaks in poultry helps to reach this aim (Ward et al., 2008).

The present study was intended to investigate the epidemiology of HPAI H5N1 in Nile delta governorates of Egypt from 2006 to 2016 in spatial and temporal patterns linking epidemiology with the dynamics of endemic H5N1 virus evolution. This would provide valuable insights to facilitate the targeted cost-effectiveness control plan. Furthermore, the current study developed a statistical model to explore the impacts of meteorological parameters and climatic conditions on the outbreak occurrence of HPAIV H5N1.

\section{MATERIALS AND METHODS}

\section{Ethical approval}

All procedures performed in this study including collection of outbreak data were in accordance with the Egyptian ethical standards of the national research committee and with agreement of Egyptian veterinary authorities.

\section{Study area}

Egypt has 29 governorates, 17 of these governorates are located in Lower Egypt, of which 11 are in the Nile Delta as it is illustrated in figure 1. The Nile delta is $40000 \mathrm{~km}^{2}$ with more than half of Egypt's population and large numbers of poultry. In commercial farms and backyards, the incidence of HPAI H5N1 virus in Lower Egypt was higher than that in Upper Egypt (Aly et al., 2008, Hafez et al., 2010). The higher incidence rate of disease was observed in the Nile Delta region where there are high densities of poultry and human populations (Arafa et al., 2016, El-Zoghby et al., 2013).

This study was carried out in five Nile Delta governorates (Sharkia, Qalyobia, Menofia, and Gharbia) of Egypt as highlighted in figure 2, where the higher numbers of disease outbreaks were reported (Arafa et al., 2016). In addition, these regions are considered as leading poultry producing governorates in Egypt (ElMasry et al., 2017).

In this study, the outbreak was defined as the incidence of disease in farms, household or whole villages. An outbreak was the unit of analysis, based on that all poultry populations in a given single village were considered infected with HPAI H5N1 even if there was only one reported outbreak within a certain circumscribed location in this village at a certain point in time. Each case was Geo-referenced by GPS coordinates where HPAI-H5N1 had been identified at a definite time.

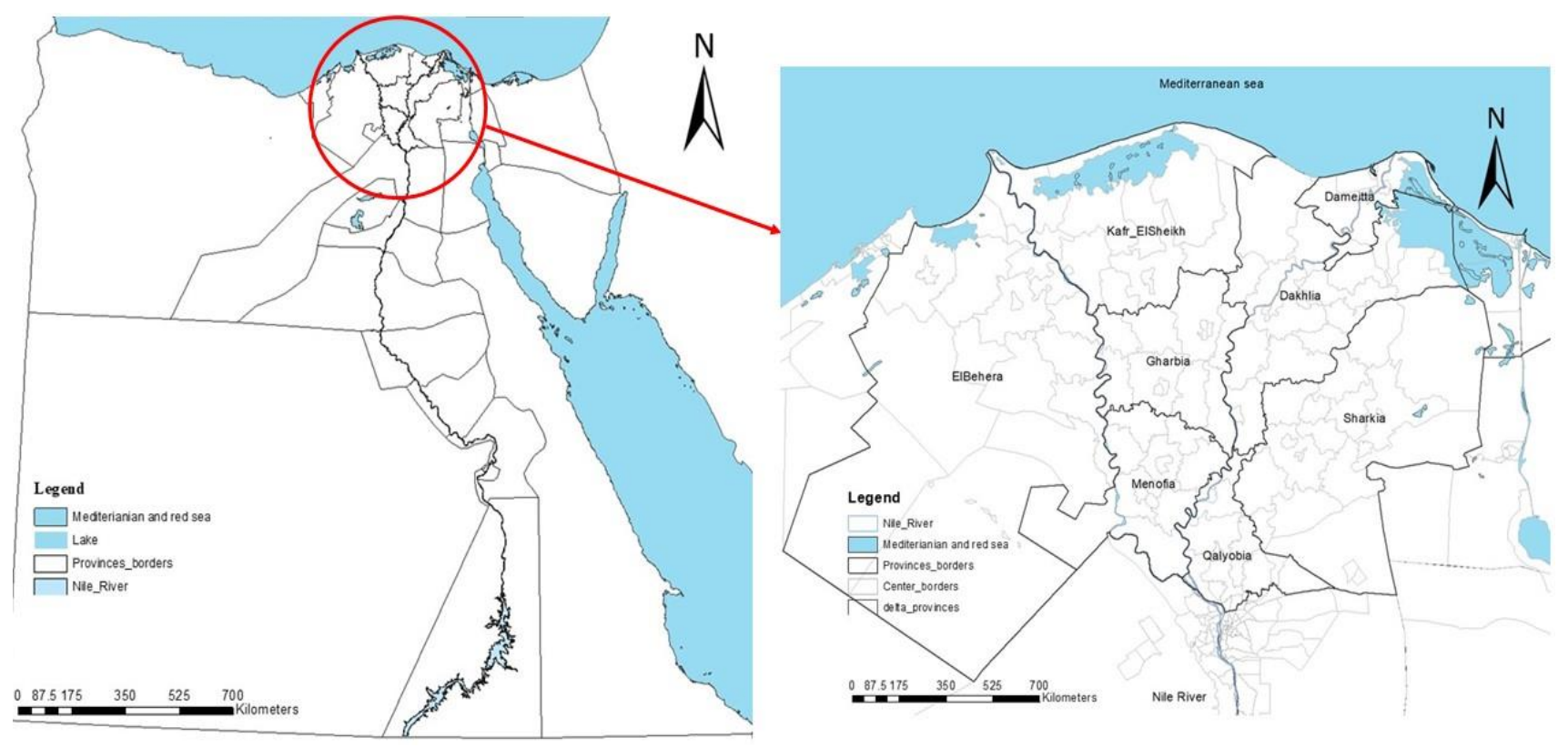

Figure 1. The map of Egyptian governorate 


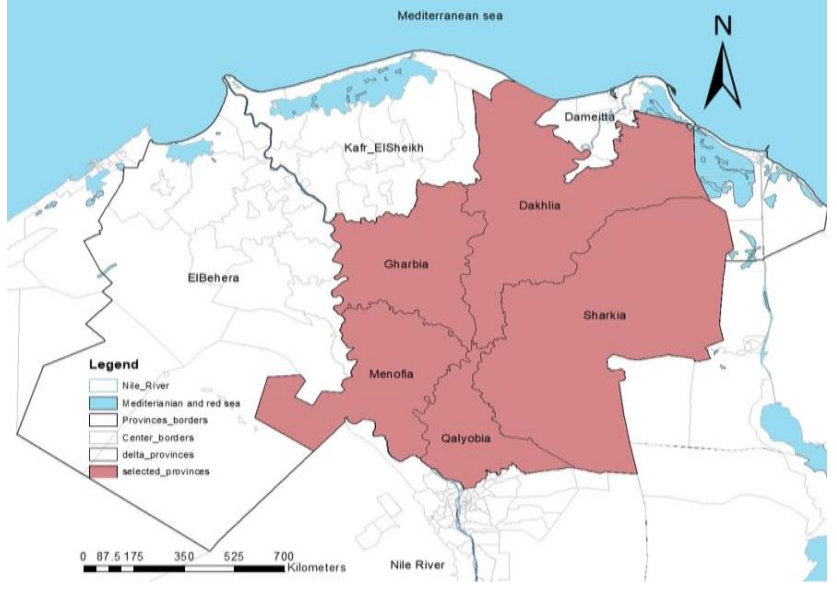

Figure 2. The map of the study area, in Nile Delta governorates (Dakhlia, Qalyobia, Sharkia, Gharbia, and Menofia) of Egypt

\section{Data source and data processing}

\section{Highly pathogenic avian influenza H5N1}

Domestic poultry HPAI-H5N1 outbreak data has been collected from the Egyptian Ministry of Agriculture (Egyptian Committee for Veterinary Services) based on official reports for national surveillance. Moreover, the database of the Global Animal Health Information System of the Food and Agricultural Organization (FAO) was obtained from the Emergency Prevention System for transboundary animal and plant pests and diseases program (EMPRES-i) (FAO 2016). All data from January 2006 to December 2016 were integrated into one dataset.

\section{Climate data}

Climatological data from January 2006 to December 2016 were downloaded from the NASA Prediction of Worldwide Energy Resources (NASA, 2019). The climatic parameters were arranged according to their spatial coordinates and outbreak times to establish its spatial linkage to HPAI-H5N1 outbreaks. In NASA, the parameters are based on solar radiation delivered from satellite observation and meteorological data from assimilation models. The parameters used in the current study were calculated from the same solar and/or meteorological values. Additionally, the respective parameters were given in units commonly employed in each user community.

\section{Statistical analysis and modeling}

The relation between numbers of poultry outbreaks and climatological risk factors was assessed by using Poisson regression through generalized linear modeling. To predict the HPAI H5N1 outbreaks in poultry, this study used Generalized Estimating Equation (GEE) model and corrected it through an offset parameter for the poultry population sizes. The GEE model was selected because of the data consisted of repeated measures of climatic data. It also accounted for over-dispersion for the number of poultry outbreaks, because one outbreak can result in other outbreaks via local transmission. The Poisson regression model was formulated for each parameter as follows:

\section{$\log (\mathrm{Y})=\log (\mathrm{N})+\mathrm{b}_{0}+\mathrm{b}_{\mathrm{i}} \mathrm{X}_{\mathrm{i}}$}

Here, $\mathrm{Y}$ denotes the expected number of poultry outbreaks, $\mathrm{N}$ is the poultry population, $\mathrm{b}_{0}$ is the intercept estimate $\mathrm{X}_{\mathrm{i}}$ is the variables tested, $\mathrm{b}_{\mathrm{i}}$ is their coefficients. Furthermore, variance $(\mathrm{Y})=\mathrm{tY}$, where $\mathrm{t}$ is the scale parameter that reflects the degree of over-dispersion. The antilog of the estimated coefficients bi corresponds to the relative risk. Univariate analysis for each variable was conducted, and those with a significance level $\mathrm{p}<0.01$ were considered significant. All statistical analyses were performed by SAS software version 9.4 and PROC GENMOD was used for the GEE models.

\section{RESULTS AND DISCUSSION}

\section{The spatial pattern of the disease}

In Egypt, there is no specific spatial distribution pattern of $\mathrm{H} 5 \mathrm{~N} 1$, which could indicate the circulation of the virus wherever the poultry is present. However, a higher rate of disease outbreaks was recorded in Delta of Lower Egypt (Arafa et al., 2016, El-Zoghby et al., 2013). Figure 3 revealed that the highest disease outbreaks were recorded at Dakhlia, Qalyobia, Sharkia, Gharbia and Menofia governorates, respectively. This finding was consistent with a previous study by Arafa et al. (2016) conducted in Lower Egypt. In addition, the highest probability of infection in Dakhlia and Qalyobia was $50 \%$ and $45 \%$, respectively. A Prevalence Rate (PR) of $50 \times 10^{3}$ infected birds per 100,000 birds was observed in Dakhlia and $45 \times 10^{3}$ infected birds per 100,000 birds were found in Qalyobia. While the lowest infection probability of $3.5 \%$, with a PR of $3.5 \times 10^{3}$ infected birds per 100,000 birds was recorded in Menofia. This finding is comparable to the results of Kayali et al. (2014) who reported the lowest and the highest detection percentage of HPAI 
H5N1 were found in Menofia and Dakhlia, respectively. This could be attributed to the highest diversity of the HA gene recorded in Dakhlia, Qalyobia and Menofia governorates which indicates active virus circulation and in favor of virus persistence (Arafa et al., 2016). Given that all virus clusters have been recorded in Dakhlia, Qalyobia, and Sharkia in different time periods, it appears that the mentioned governorates are popular locations for virus transmission, which has been proved by (Arafa et al., 2016; Scotch et al., 2013).

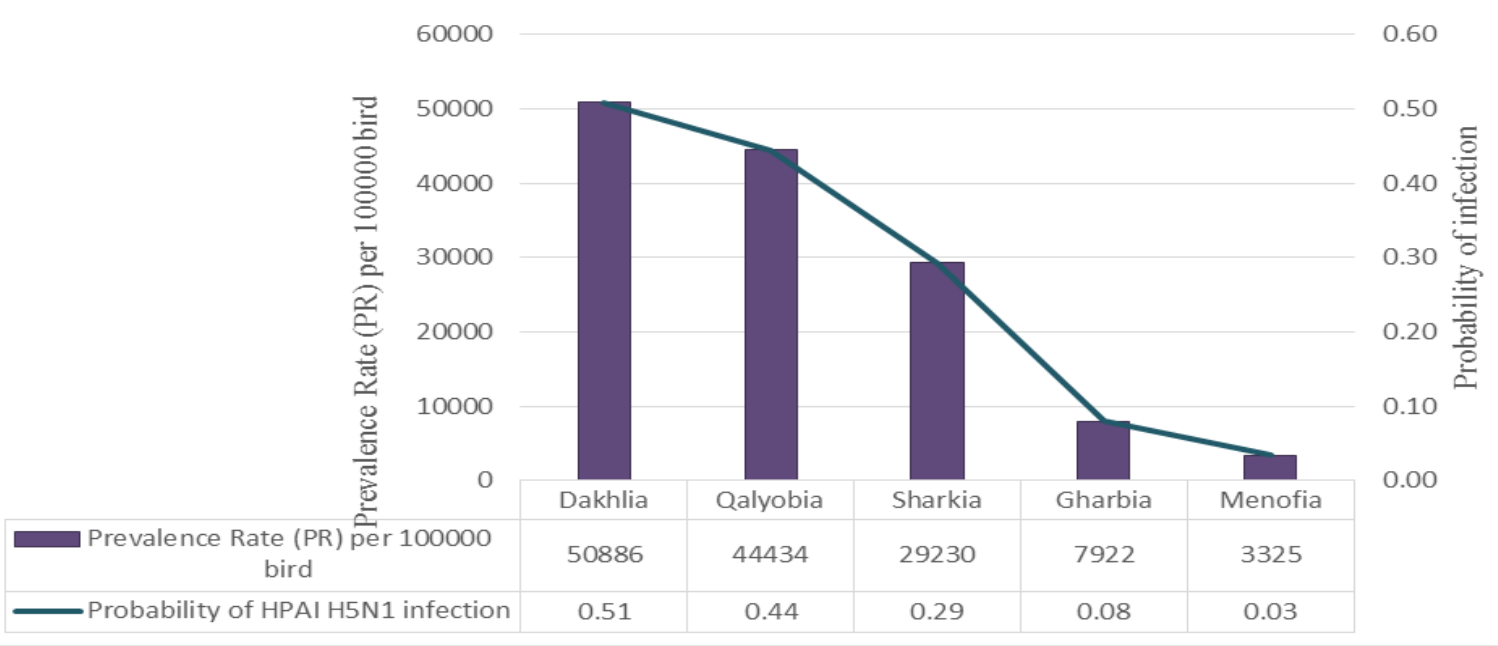

Figure 3. The Prevalence rate and probability of highly pathogenic avian influenza H5N1 infection in the Nile Delta governorates (Dakhlia, Qalyobia, Sharkia, Gharbia, and Menofia) of Egypt from 2006 to 2016

\section{Temporal pattern of the disease}

The time series analysis presented in figure 4 clearly confirmed the endemicity of H5N1 virus in Dakhlia, Qalyobia, Sharkia, Gharbia and Menofia governorates from 2006 to 2016. HPAI H5N1 cases have been continuously reported every year since the first occurrence of the disease in 2006. These results are the same as those reported by the previous study in Egypt (Arafa et al., 2016). Considering temporal distribution shown in figure 4, the highest PR was observed in 2006 with $15 \times 10^{3}$ infected birds per 100,000 bird then the PR declined sharply to around $3 \times 10^{3}$ infected birds per 100,000 bird in 2007, 2008 and 2009. This sharp decline can be attributed to effective control strategies such as vaccination and containment following outbreak detection. It may also be associated with underreporting of the disease due to fear of culling and inadequate compensation. As well as, there is a shortage in the notification of disease in the poultry industry in Egypt (FAO, 2011). It could also be explained as the classic clade 2.2.1 was predominant and remained stable from 2006 to 2009 (Arafa et al., 2016). Continuous improper vaccination in Egypt resulted in emerging of antigenically different viruses in 2007 (Balish et al., 2010; Cattoli et al., 2011). Two variant clades 2.2.1.1 and 2.2.1.1 a had emerged from the classic clade 2.2.1. The 2.2.1.1 clade evolved in late 2007 to 2009, while the clade 2.2.1.1a emerged in 2008 and remained until 2011. After that, there are no reports for the detection of the variant clusters (Arafa et al., 2016).

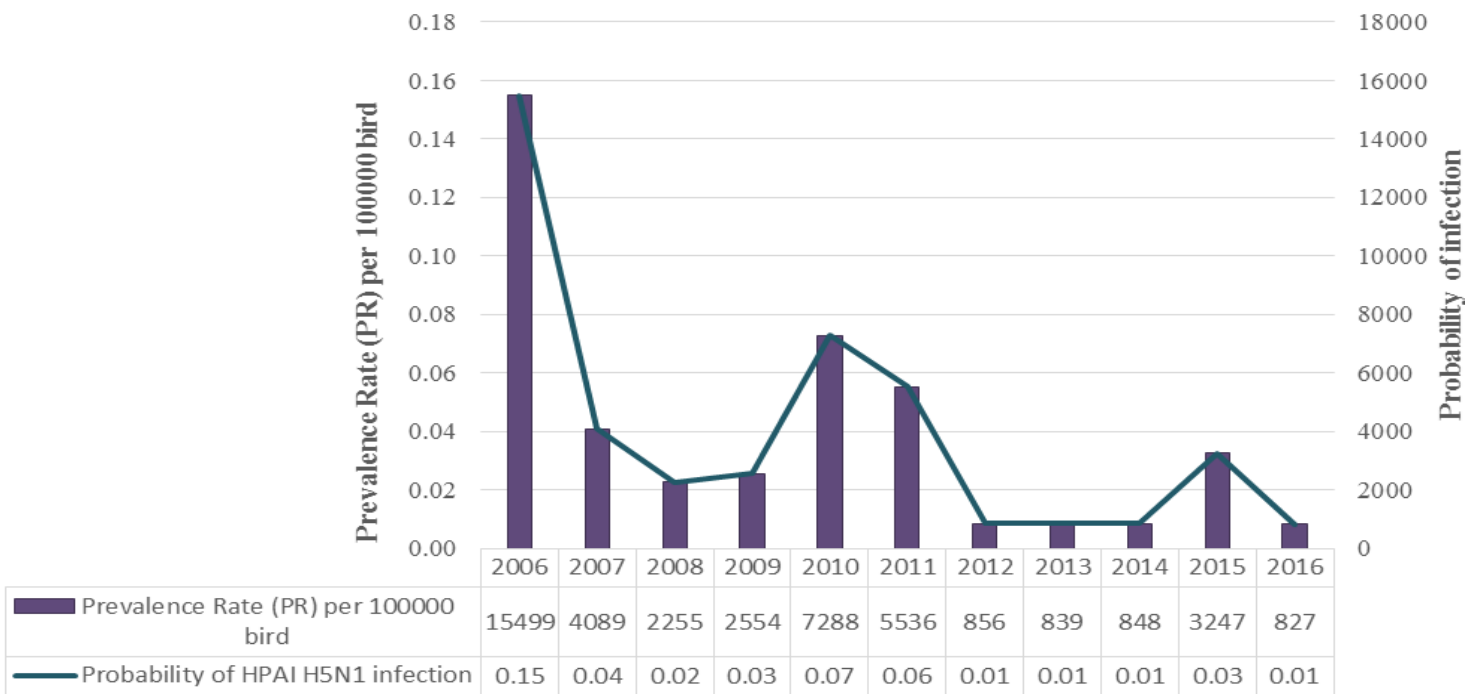

Figure 4. The estimated prevalence rate of highly pathogenic avian influenza H5N1 in Nile Delta governorates (Dakhlia, Qalyobia, Sharkia, Gharbia, and Menofia) of Egypt from 2006 to 2016 
In figure 4, the PR again increased from 2008 till it reached the first peak in 2010 with a rate of $7 \times 10^{3}$ infected birds per 100,000 birds then declined again and became almost stable from 2012 to 2014. The second cluster peak was observed in 2015 with a PR of $3 \times 10^{3}$ infected birds per 100,000 birds. The rising of PR along with the highest peak in 2008 until 2010 and the emergence and rapid spread of clade 2.2.1.1 highlight the selective advantages of these viruses in vaccinated birds. The following sharp decline reflected the period of the extinction of the 2.2.1.1 variant strains. Despite there are no available clear reasons for exclusion of this clade, the adaptation of vaccines to these viruses had been occurred (Naguib et al., 2016).

The gradual accumulation of genetic mutations in the HA protein resulted in emerging of the endemic clade 2.2.1.2 that was first identified in Egypt in 2008 and became the dominant detected cluster between 2009 and 2014 in both commercial and household poultry sectors (Arafa et al., 2016; El-Shesheny et al., 2014). Therefore, it may indicate that the same virus was circulating undetected from 2008 to 2010. In addition, the observed stability in PR from 2012 to 2014 can be attributed to the high adaptation capability of the clade 2.2.1.2 in poultry and environment, therefore it is considered as an endemic cluster (Arafa et al., 2012).

As shown in figure 4, the second-highest peak in 2015 could be explained by the obtained predominance nature of the distinct cluster of 2.2.1.2 HPAI H5N1 virus since summer 2014 followed by a sudden rise in poultry houses in late 2014 (Arafa et al., 2015). Since November 2014, in parallel with the rising of virus activity among poultry, viruses of this cluster were also associated with a huge increased incidence of human H5N1 infections in Egypt (Arafa et al., 2015). Furthermore, the high frequency of HPAIV H5N1 outbreaks in poultry was correlated with increased rates of human infections from 2014 to 2015 (Naguib et al., 2016). This finding can be related to the increased binding affinity of the widely circulated virus (clade 2.2.1.2) to human receptors due to mutations (Arafa et al., 2016). This led to enhance poultry-to-human transmission cases, in addition to an increase in the rate of evolution in all genomic segments of the virus compared to the predecessor 2.2.1 clade. In all poultry production systems throughout the country, high evolutionary dynamics of H5N1 viruses were observed (Arafa et al., 2016), leading to the outbreaks in several successive peaks along with the virus evolution. Also, Naguib et al. (2016) declared that antigenic drift in the virus since its introduction in 2006 confirmed the rapid evolution of H5N1 HPAIV in Egypt.

In this regard, H5N1 viruses in Egypt have progressive evolution rate which could be attributed to sub-optimal use of vaccines resulting in virus persistence for long periods in the environment which led to the endemic prevalence of 2.2.1.2 viruses along six consecutive years (Arafa et al., 2016; Cattoli et al., 2011). Cattoli et al. (2011) concluded that positive selection and evolutionary dynamics of viruses significantly increased in countries which applied the vaccination against $\mathrm{H} 5 \mathrm{~N} 1$ viruses in poultry compared to countries that had never applied vaccination.

\section{Modeling highly pathogenic avian influenza outbreaks and the meteorological parameters}

Table 1 was designed to estimate the association between the climatic factors and the risk of HPAI outbreaks in the Nile Delta governorates through the period from 2006 to 2016, and only covers the periods of outbreak occurrence collectively, regardless of seasons. It was based on the Poisson models fitted with GEEs. The number of poultry outbreaks was univariately associated with maximum and minimum temperature, relative humidity, dewpoint temperature, and maximum wind speed $(\mathrm{p}<0.05)$. The number of poultry outbreaks was negatively correlated with all climatic parameters except for the relative humidity which showed a positive association with outbreaks.

The estimated coefficients and effects of the GEE model are shown in table 1. The estimated coefficient of temperature was negative and statistically significant, suggesting that outbreak probability decreases as temperatures rise. In particular, an increase of one-unit in maximum temperature reduced the risk of outbreaks in poultry by about $6 \%$. As well as, a one-unit increase in minimum and dewpoint temperature decreased the risk of poultry outbreaks by $4 \%$. Nevertheless, the negative association between outbreaks and temperature was consistent with findings of previous literature (Liu et al., 2007; Mu et al., 2011; Tiensin et al., 2007; Zhang et al., 2010). While a one-unit increase in relative humidity was related to $1 \%$ increase in the outbreak. In addition, a one-unit increase in minimum wind speed at two meters above ground decreased the risk of the outbreak by $5 \%$. This can be explained by the fact that the dispersion effect of wind on virus load in the air reduces the ability of the virus to cause infection.

Despite the strong established association between environmental temperature and HPAI-H5N1 outbreaks (Zhang et al. 2014), the results of the current study on some Nile Delta governorates showed a lower effect of temperature on the outbreak occurrence. This could be supported by the reported sporadic outbreaks throughout the year in poultry and human which was recently described in several studies (Aly et al., 2008; Arafa et al., 2016; Hafez et al., 2010; WHO, 2010). Aly et al. (2008) and Hafez et al. (2010) demonstrated the association of H5N1 virus infection to the winter season in Egypt during 2006-2008, with a decreased incidence throughout summer and autumn months. This might be explained by the classic clade 2.2.1 which was predominant and remained stable from 2006 to 2009 (Arafa et al., 2016). While since 2009 the classic viruses evolved into a new clade and the epidemiology of HPAI virus and temporal patterns have been changed. The outbreaks occur in the warm-season and the virus is circulated throughout the year (Abdelwhab and Hafez 2011; Cattoli et al., 2011). 
Table 1. Estimation of the association between meteorological parameters and the risk of highly pathogenic avian influenza outbreaks from 2006 to 2016, in Nile Delta governorates (Dakhlia, Qalyobia, Sharkia, Gharbia and Menofia), Egypt

\begin{tabular}{|c|c|c|c|c|c|}
\hline $\begin{array}{l}\text { Meteorological } \\
\text { parameters }\end{array}$ & Parameter & $\begin{array}{c}95 \% \text { CI estimate } \\
\text { (upper and lower confidence limits) }\end{array}$ & $\begin{array}{c}\text { P-value } \\
(\operatorname{Pr}>|Z|)\end{array}$ & Crude RR $(95 \%$ CI) & Effect \\
\hline \multirow{2}{*}{$\begin{array}{l}\text { Relative } \\
\text { humidity }\end{array}$} & Intercept & $\begin{array}{c}-15.5315 \\
(-16.5321--14.5308)\end{array}$ & $<.0001$ & $\begin{array}{c}1.01223 \\
(1.00398-1.02056)\end{array}$ & $1.22 \%$ \\
\hline & Parameter & $\begin{array}{c}0.0122 \\
(-16.5321--14.5308)\end{array}$ & 0.0036 & & \\
\hline \multirow{2}{*}{$\begin{array}{l}\text { Dewpoint } \\
\text { temperature }\end{array}$} & Intercept & $\begin{array}{c}-14.0755 \\
(-16.5321--14.5308)\end{array}$ & $<.0001$ & $\begin{array}{c}0.95802 \\
(0.94837-0.96778)\end{array}$ & $-4.20 \%$ \\
\hline & Parameter & $\begin{array}{c}-0.0429 \\
(-16.5321--14.5308)\end{array}$ & $<.0001$ & & \\
\hline \multirow{2}{*}{$\begin{array}{l}\text { Maximum } \\
\text { temperature }\end{array}$} & Intercept & $\begin{array}{c}-14.3421 \\
(-16.5321--14.5308) \\
\end{array}$ & $<.0001$ & $\begin{array}{c}0.93504 \\
(0.91176-0.9589)\end{array}$ & $-6.50 \%$ \\
\hline & Parameter & $\begin{array}{c}-0.0672 \\
(-16.5321--14.5308)\end{array}$ & $<.0001$ & & \\
\hline \multirow{2}{*}{$\begin{array}{l}\text { Minimum } \\
\text { temperature }\end{array}$} & Intercept & $\begin{array}{c}-13.8926 \\
(-16.5321--14.5308)\end{array}$ & $<.0001$ & $\begin{array}{c}0.96381 \\
(0.95635-0.97133)\end{array}$ & $-3.62 \%$ \\
\hline & Parameter & $\begin{array}{c}-0.0369 \\
(-16.5321--14.5308)\end{array}$ & $<.0001$ & & \\
\hline \multirow{2}{*}{$\begin{array}{l}\text { Maximum wind } \\
\text { speed }\end{array}$} & Intercept & $\begin{array}{c}-14.2385 \\
(-16.5321--14.5308)\end{array}$ & $<.0001$ & $\begin{array}{c}0.95034 \\
(0.93643-0.96445)\end{array}$ & $-4.97 \%$ \\
\hline & Parameter & $\begin{array}{c}-0.0509 \\
(-16.5321--14.5308) \\
\end{array}$ & $<.0001$ & & \\
\hline
\end{tabular}

CI: confidence interval, RR: relative risk

\section{CONCLUSION}

This study concluded that the high evolutionary dynamics of the Egyptian H5N1 viruses led to the appearance of outbreaks in several successive peaks along with the virus evolution. Results from the GEE model indicated that the effect of temperature on outbreak occurrence is lower than that reported by previous studies. This finding is supported by the sporadic outbreaks that have occurred throughout the year in poultry and human since 2009. The classic viruses evolved into new clades and the epidemiology of HPAI virus and temporal patterns have been changed. Hence, the viruses circulate all year round and outbreaks occur in the warm season. Continuous monitoring of spatiotemporal patterns of the circulating viruses is necessary to improve the cost-effectiveness of disease control and prevention.

\section{DECLARATIONS}

\section{Acknowledgments}

The authors extend their appreciation to Dr. Gamal El Afandi, (College of Agriculture, Environment and Nutrition Sciences, Tuskegee University, Tuskegee, AL 36088, USA) for his kind support during the study.

\section{Competing interests}

The authors declare that they have no competing interests.

\section{Authors' contributions}

Dr. Ghada Hadad collected the data, Dr. Mona Aly obtained the data, Dr. Gamal El Afandi designed the analysis, Dr. Gamal El Afandi and Yumna Aladdin were responsible for analysis and manuscript writing, Dr. Sherif Zidan revised the manuscript, and Dr. Ahmed Byomi critically revised the manuscript for important intellectual contents. All authors approved the final version of the manuscript.

\section{REFERENCES}

Abdelwhab E and Hafez H (2011). An overview of the epidemic of highly pathogenic H5N1 avian influenza virus in Egypt: epidemiology and control challenges. Epidemiology and Infection, 139 (5): 647-657. DOI: https://doi.org/10.1017/S0950268810003122

Abdelwhab E, Selim A, Arafa A, Galal S, Kilany W, Hassan M, Aly M and Hafez M (2010). Circulation of avian influenza H5N1 in live bird markets in Egypt. Avian Diseases, 54 (2): 911-914. DOI: https://doi.org/10.1637/9099-100809-RESNOTE.1

Aly M, Arafa A and Hassan M (2008). Epidemiological findings of outbreaks of disease caused by highly pathogenic H5N1 avian influenza virus in poultry in Egypt during 2006. Avian Diseases, 52 (2): 269-277. DOI: https://doi.org/10.1637/8166-103007Reg.1 
Arafa A, Suarez D, Kholosy S, Hassan M, Nasef S, Selim A, Dauphin G, Kim M, Yilma J and Swayne D (2012). Evolution of highly pathogenic avian influenza H5N1 viruses in Egypt indicating progressive adaptation. Archives of Virology, 157 (10): 1931-1947. DOI: https://doi.org/10.1007/s00705-012-1385-9

Arafa A, Naguib M, Luttermann C, Selim A, Kilany W, Hagag N, Samy A, Abdelhalim A, Hassan M and Abdelwhab E (2015). Emergence of a novel cluster of influenza A (H5N1) virus clade 2.2. 1.2 with putative human health impact in Egypt, 2014/15. Eurosurveillance, 20 (13): 21085. DOI: https://doi.org/10.2807/1560-7917.ES2015.20.13.21085

Arafa A, El-Masry I, Khoulosy S, Hassan MK, Soliman M, Fasanmi OG, Fasina FO, Dauphin G, Lubroth J and Jobre YM (2016). Predominance and geo-mapping of avian influenza $\mathrm{H} 5 \mathrm{~N} 1$ in poultry sectors in Egypt. Geospatial Health. DOI: https://doi.org/10.4081/gh.2016.492

Balish AL, Davis CT, Saad MD, El-Sayed N, Esmat H, Tjaden JA, Earhart KC, Ahmed LaE, El-Halem MA and Ali AHM (2010). Antigenic and genetic diversity of highly pathogenic avian influenza A (H5N1) viruses isolated in Egypt. Avian Diseases, 54 (1): 329-334. DOI: https://doi.org/10.1637/8903-042909-Reg.1

Capua I and Alexander D (2010). Perspectives on the global threat: the challenge of avian influenza viruses for the world's veterinary community. Avian Diseases, 54 (1): 176-178. DOI: https://doi.org/10.1637/8870-041009-Reg.1

Cattoli G, Fusaro A, Monne I, Coven F, Joannis T, El-Hamid HSA, Hussein AA, Cornelius C, Amarin NM and Mancin M (2011). Evidence for differing evolutionary dynamics of A/H5N1 viruses among countries applying or not applying avian influenza vaccination in poultry. Vaccine, 29 (50): 9368-9375. DOI: https://doi.org/10.1016/j.vaccine.2011.09.127

Claas EC, Osterhaus AD, Van Beek R, De Jong JC, Rimmelzwaan GF, Senne DA, Krauss S, Shortridge KF and Webster RG (1998). Human influenza A H5N1 virus related to a highly pathogenic avian influenza virus. The Lancet, 351 (9101): 472-477. DOI: https://doi.org/10.1016/S0140-6736(97)11212-0

El-Shesheny R, Kandeil A, Bagato O, Maatouq AM, Moatasim Y, Rubrum A, Song M-S, Webby RJ, Ali MA and Kayali G (2014). Molecular characterization of avian influenza H5N1 virus in Egypt and the emergence of a novel endemic subclade. The Journal of General Virology, 95 (7): 1444. DOI: https://doi.org/10.1099/vir.0.063495-0

El-Zoghby EF, Aly MM, Nasef SA, Hassan MK, Arafa A-S, Selim AA, Kholousy SG, Kilany WH, Safwat M and Abdelwhab E (2013). Surveillance on A/H5N1 virus in domestic poultry and wild birds in Egypt. Virology Journal, 10 (1): 203. DOI: https://doi.org/10.1186/1743-422X-10-203

ElMasry I, Elshiekh H, Abdlenabi A, Saad A, Arafa A, Fasina FO, Lubroth J and Jobre Y (2017). Avian influenza H5N1 surveillance and its dynamics in poultry in live bird markets, Egypt. Transboundary and Emerging Diseases, 64 (3): 805-814. DOI: https://doi.org/10.1111/tbed.12440

FAO (2009). Global disease information system [Internet]. Available at: http://empresi.fao.org/empres-i/home.

FAO (2011). Approaches to controlling, preventing and eliminating H5N1 highly pathogenic avian influenza in endemic countries. Available at: http://www.fao.org/docrep/014/i2150e/i2150e.pdf.

FAO (2013). Mapping influenza A (H5N1) virus transmission pathways and critical control points in Egypt. Food and Agriculture Organization, Rome, Italy. Available at: http://www.fao.org/docrep/017/i3272e/i3272e.pdf.

FAO (2016). Global animal disease information system (EMPRES-i). Available at: http://www.fao.org/ag/AGA/AGAH/EMPRES/

Gilbert M and Pfeiffer DU (2012). Risk factor modelling of the spatio-temporal patterns of highly pathogenic avian influenza (HPAIV) H5N1: a review. Spatial and Spatio-temporal Epidemiology, 3 (3): 173-183. DOI: https://doi.org/10.1016/j.sste.2012.01.002

Gilbert M, Slingenbergh J and Xiao X (2008). Climate change and avian influenza. Revue Scientifique et Technique (International Office of Epizootics), 27 (2): 459. DOI: https://doi.org/10.20506/rst.27.2.1821

Hafez M, Arafa A, Abdelwhab E, Selim A, Khoulosy S, Hassan M and Aly M (2010). Avian influenza H5N1 virus infections in vaccinated commercial and backyard poultry in Egypt. Poultry Science, 89 (8): 1609-1613. DOI: https://doi.org/10.3382/ps.201000708

Kayali G, Kandeil A, El-Shesheny R, Kayed AS, Gomaa MM, Maatouq AM, Shehata MM, Moatasim Y, Bagato O and Cai Z (2014). Active surveillance for avian influenza virus, Egypt, 2010-2012. Emerging Infectious Diseases, 20 (4): 542. DOI: https://doi.org/10.3201/eid2004.131295

Liu C-M, Lin S-H, Chen Y-C, Lin KC-M, Wu T-SJ and King C-C (2007). Temperature drops and the onset of severe avian influenza A H5N1 virus outbreaks. PLoS One, 2 (2): e191. DOI: https://doi.org/10.1371/journal.pone.0000191

$\mathrm{Mu} \mathrm{JH}, \mathrm{McCarl} \mathrm{BA}, \mathrm{Wu} \mathrm{X}$ and Gan L (2011). Climate Change Influences on the Risk of Avian Influenza Outbreaks and Associated Economic Loss. Agricultural and Applied Economics Association 2011 Annual Meeting. Available at: https://ageconsearch.umn.edu/record/103637/.

Naguib MM, Abdelwhab E and Harder TC (2016). Evolutionary features of influenza A/H5N1 virus populations in Egypt: poultry and human health implications. Archives of Virology, 161 (7): 1963-1967. DOI: https://doi.org/10.1007/s00705-016-2849-0

National Aeronautics and Space Administration (NASA) (2019). Prediction of Worldwide Energy Resources. POWER Release-8. Available at: https://power.larc.nasa.gov/\#resources.

Park AW and Glass K (2007). Dynamic patterns of avian and human influenza in east and southeast Asia. The Lancet Infectious Diseases, 7 (8): 543-548. DOI: https://doi.org/10.1016/S1473-3099(07)70186-X

Pfeiffer DU, Minh PQ, Martin V, Epprecht M and Otte MJ (2007). An analysis of the spatial and temporal patterns of highly pathogenic avian influenza occurrence in Vietnam using national surveillance data. The Veterinary Journal, 174 (2): $302-309$. DOI: https://doi.org/10.1016/j.tvj1.2007.05.010

Scotch M, Mei C, Makonnen YJ, Pinto J, Ali A, Vegso S, Kane M, Sarkar IN and Rabinowitz P (2013). Phylogeography of influenza A H5N1 clade 2.2. 1.1 in Egypt. BMC Genomics, 14 (1): 871. DOI: https://doi.org/10.1186/1471-2164-14-871 
Tiensin T, Nielen M, Songserm T, Kalpravidh W, Chaitaweesub P, Amonsin A, Chotiprasatintara S, Chaisingh A, Damrongwatanapokin S and Wongkasemjit S (2007). Geographic and temporal distribution of highly pathogenic avian influenza A virus (H5N1) in Thailand, 2004-2005: an overview. Avian Diseases, 51 (s1): 182-188. DOI: https://doi.org/10.1637/7635042806R.1

World Animal Health Information Database (WAHID) (2011). Available at: http://www.oie.int/wahis/public.php?page=home.

Ward MP, Maftei D, Apostu C and Suru A (2008). Geostatistical visualisation and spatial statistics for evaluation of the dispersion of epidemic highly pathogenic avian influenza subtype H5N1. Veterinary Research, 39 (3): 1. DOI: https://doi.org/10.1051/vetres:2007063

WHO-EMRO (2015). Egypt: upsurge in H5N1 human and poultry cases but no change in transmission pattern of infection, 2015. World Health Organization Regional Office for Eastern Mediterranean, Cairo, Egypt.

Available at: http://www.emro.who.int/egy/egypt-news/upsurge-h5n1-human-poultry-cases-may-2015.html.

WHO (2010). Situation updates - avian influenza. Available at: (http://www.who.int/csr/disease/avian_influenza/updates/en/index.html). .

Xu X, Subbarao K, Cox NJ and Guo Y (1999). Genetic characterization of the pathogenic influenza A/Goose/Guangdong/1/96 (H5N1) virus: similarity of its hemagglutinin gene to those of H5N1 viruses from the 1997 outbreaks in Hong Kong. Virology, 261 (1): 15-19. DOI: https://doi.org/10.1006/viro.1999.9820

Yupiana Y, de Vlas SJ, Adnan NM and Richardus JH (2010). Risk factors of poultry outbreaks and human cases of H5N1 avian influenza virus infection in West Java Province, Indonesia. International Journal of Infectious Diseases, 14 (9): e800-e805. DOI: https://doi.org/10.1016/j.ijid.2010.03.014

Zhang Z, Chen D, Liu W and Wang L (2010). Evaluating the impact of climate change on global HPAI H5N1 outbreaks. International Congress on Environmental Modelling and Software, 36. DOI: https://doi.org/10.1371/journal.pone.0015314

Zhang Z, Chen D, Chen Y, Davies TM, Vaillancourt J-P and Liu W (2012). Risk signals of an influenza pandemic caused by highly pathogenic avian influenza subtype H5N1: spatio-temporal perspectives. The Veterinary Journal, 192 (3): 417-421. DOI: https://doi.org/10.1016/j.tvj1.2011.08.012

Zhang Z, Chen D, Chen Y, Wang B, Hu Y, Gao J, Sun L, Li R and Xiong C (2014). Evaluating the impact of environmental temperature on global highly pathogenic avian influenza (HPAI) H5N1 outbreaks in domestic poultry. International Journal of Environmental Research and Public Health, 11 (6): 6388-6399. DOI: https://doi.org/10.3390/ijerph110606388

Zhou L, Liao Q, Dong L, Huai Y, Bai T, Xiang N, Shu Y, Liu W, Wang S and Qin P (2009). Risk factors for human illness with avian influenza A (H5N1) Virus infection in China. The Journal of Infectious Diseases, 199 (12): 1726-1734. DOI: https://doi.org/10.1086/599206 